\title{
Phosphor Converted Three-Band White LED
}

\author{
Young-Duk Huh, Jong-Yun Park, Seok-Soon Kweon, Ji-Hyun Kim, Jong-Gyu Kim, and Young Rag Do ${ }^{\dagger}$ \\ Department of Chemistry Dankook Universitw, Seoul 140-71 4 , Korea \\ ${ }^{\dagger}$ Department of Chemistry, Kookmin Universitw, Seoul 136-702, Korea \\ Received Mav 23, 2004
}

Key Words : Blue LED. White LED. SrGa $\mathrm{S}_{4}: E u, \mathrm{SrY}_{2} \mathrm{~S}_{4}: \mathrm{Eu}$

The development of wide band gap III-V nitride compound semiconductors has led to the commercial production of high-efficiency LEDs. ${ }^{1.2}$ The recent advent of blue $\mathrm{LnGaN}$ teclnology has made it possible to produce a conventional white LED in which white light is obtained by coating a $\mathrm{Y}_{3} \mathrm{Al}_{5} \mathrm{O}_{12} \mathrm{Ce}$ (or $\mathrm{Sr}_{3} \mathrm{SiO}_{5}: \mathrm{Eu}$ ) phosphor onto a blue LED chip. ${ }^{3 \cdot 6}$ In this device, known as a two-band white LED. white light is generated by additive color mixing of the blue light emitted by the blue LED and the yellow light emitted by the $\mathrm{Y}_{3} \mathrm{Al}_{5} \mathrm{O}_{1}: \mathrm{Ce}$ phosphor. The development of a white LED is important because it opens the way for LED applications such as light bulbs and fluorescent lamps with high durability and low energy consumption. However, the spectral composition of the light produced by the conventional two-band white LED differs from that of natural white light. particularly in the red region. The color properties of conventional two-band white LEDs can potentially be improved by adding another component to create a white LED based on three enission bands (a three-band white LED).

Full-color fluorescent display devices have been developed by using a combination of $\mathrm{ZnS}: \mathrm{Ag}$ (blue), $\mathrm{ZnS}: \mathrm{Cu} . \mathrm{Al}$ (green), and $\mathrm{ZnCdS}: \mathrm{Ag}$ (red) phosphors excited by a nearUV LED. $^{7}$ In addition, a white light source has been obtained by intergrating $\mathrm{ZnS}: \mathrm{Ag}$ (blue), $\mathrm{ZnS}: \mathrm{Cu}$ Al (green). and $\mathrm{Y}_{2} \mathrm{O}_{-} \mathrm{S}: \mathrm{Eu}$ (red) phosphors. and a UV-LED (350 $\left.\mathrm{nm}\right){ }^{8}$ White light has also been achieved by combining a blue LED (460 nm) with $\mathrm{SrGa}_{2} \mathrm{~S}_{4}: \mathrm{Eu}$ (green) and $\mathrm{SrS}: \mathrm{Eu}$ (red) phosphors. ${ }^{9}$ Previously, we constructed a three-band white LED by combining a blue LED (465 lint) with $\mathrm{SrGa}_{2} \mathrm{~S}_{4}: \mathrm{Eu}$ (green) and $\mathrm{ZnCdS} \cdot \mathrm{Ag}, \mathrm{Cl}$ (red) phosphors. ${ }^{\text {li }}$ In the present work, we investigated the optical properties of a white LED which was obtained by using a blue LED ( $465 \mathrm{~nm})$ in conjunction with $\mathrm{SrGa}_{2} \mathrm{~S}_{4}: \mathrm{Eu}$ (green) and $\mathrm{SrY}_{2} \mathrm{~S}_{4}: \mathrm{Eu}$ (red) phosphors. The $\mathrm{SrY}_{2} \mathrm{~S}_{4}$ Eu phosphor was chosen over the ZnCdS:Ag,Cl phosphor used in our previous work in order to improve the red color characteristics of the white LED.

\section{Experimental Section}

Green-emitting $\mathrm{SrGa}_{2} \mathrm{~S}_{4}: \mathrm{Eu}$ phosphor was synthesized using a decomposition method that does not involve the use

${ }^{*}$ Corresponding Author. Tel: +82-2-709-2409: Fax: -82-2-792-9269: e-mail: ydhuhitadankook.ac.kr of the toxic compound hydrogen sulfide. $\mathrm{SrGa}_{2} \mathrm{~S}_{4}: \mathrm{Eu}$ was synthesized by heating $0.95 \mathrm{mmol}$ of strontium sulfide $(\mathrm{SrS})$, $2.0 \mathrm{mmol}$ of gallium dimethyldithiocarbanate $\left(\mathrm{Ga}\left[\left(\mathrm{CH}_{3}\right)_{2-}\right.\right.$ $\left.\left.\mathrm{NCS}_{2}\right]_{3}\right), 0.05 \mathrm{mmol}$ of the europium complex $\left\{\left[\left(\mathrm{CH}_{3}\right)_{4} \mathrm{~N}\right]\right.$ $\left.\mathrm{Eu}\left[\left(\mathrm{CH}_{3}\right)_{2} \mathrm{NCS}_{2}\right]_{4}\right\}$. and excess sulfur for 2 hours at 850 ${ }^{\circ} \mathrm{C} .{ }^{11,11}$ However, the red-enitting $\mathrm{SrY}_{2} \mathrm{~S}_{4}$ :Eu phosphor could not be synthesized using this decomposition method; instead, it was prepared by solid-state reaction of $0.98 \mathrm{mmol}$ $\mathrm{SrCO}_{3} .2 .0 \mathrm{mmol} \mathrm{Y}_{2} \mathrm{CO}_{3} .0 .02 \mathrm{mmol}$ of $\mathrm{Eu}_{2} \mathrm{CO}_{3}$. and the appropriate amount of $\mathrm{Na}_{2} \mathrm{CO}_{3}$ as a flux, at $1300^{\circ} \mathrm{C}$ for 8 hours in $\mathrm{H}_{2} \mathrm{~S}$ stean. ${ }^{12}$

Photoluminescence (PL) excitation and emission measurements were carried out using a $0.275 \mathrm{~mm}$ monochromator. a photomultiplier tube. and a $500 \mathrm{~W}$ Xe lamp as an excitation source. The incident beam was perpendicular to the surface of the sample, and the observation angle was $45^{\circ}$ to the excitation source. The PL and cluromaticity of the three-band white LED were measured using a $15 \mathrm{~cm}$ diameter integration sphere. A blue LED (Nichia. $\lambda_{\text {n1ax }}=465 \mathrm{~nm}$ ) was used. One gram of $\mathrm{SrGa}_{2} \mathrm{~S}_{4}: \mathrm{Eu}$ or $\mathrm{SrY}_{2} \mathrm{~S}_{4}:$ Eu phosphor was dispersed in an aqueous solution containing $4.0 \mathrm{~g}$ of polyvinyl-alcohol (polymerization degree: 200). This solution was applied onto a poly (etlylene terephthalate) (PET) film. Although. the thickness and concentration of the film were not measured. the relative amounts of phosphor could be varied by adjusting the number of phosphor flims.

\section{Results and Discussion}

Figure 1 shows the PL excitation and emission spectra of the $\mathrm{SrGa}_{2} \mathrm{~S}_{4}: \mathrm{Eu}$ and $\mathrm{SrY}_{2} \mathrm{~S}_{4}: \mathrm{Eu}$ phosphors. The excitation spectra show that both phosphors absorb strongly absorptions at $465 \mathrm{rum}$, which is the emission wavelength of the blue LED used. The emission spectra show that. under 465 num excitation. the $\mathrm{SrGa}_{2} \mathrm{~S}_{4}: \mathrm{Eu}$ and $\mathrm{SrY}_{2} \mathrm{~S}_{4}: \mathrm{Eu}$ phosphors emit green $(535 \mathrm{~nm})$ and red $(640 \mathrm{~nm})$. respectively. Therefore, $\mathrm{SrGa}_{2} \mathrm{~S}_{4}: \mathrm{Eu}$ and $\mathrm{SrY}_{2} \mathrm{~S}_{4}: \mathrm{Eu}$ are suitable as greenand red-emitting phosphors when excited by a blue LED.

Figure 2(A) shows the PL spectra of blue- and greenemitting LEDs prepared by coating the blue LED with $\mathrm{SrGa}_{2} \mathrm{~S}_{4}: \mathrm{Eu}$. Two distinct emission peaks are observed at $465 \mathrm{~nm}$ and $535 \mathrm{~nm}$. which correspond to the wavelengths of the blue LED and green emission from the $\mathrm{SrGa}_{2} \mathrm{~S}_{4}: \mathrm{Eu}$ phosphor. respectively. As the amount of $\mathrm{SrGa}_{2} \mathrm{~S}_{4}: \mathrm{Eu}$ phosphor is increased by increasing the number of 


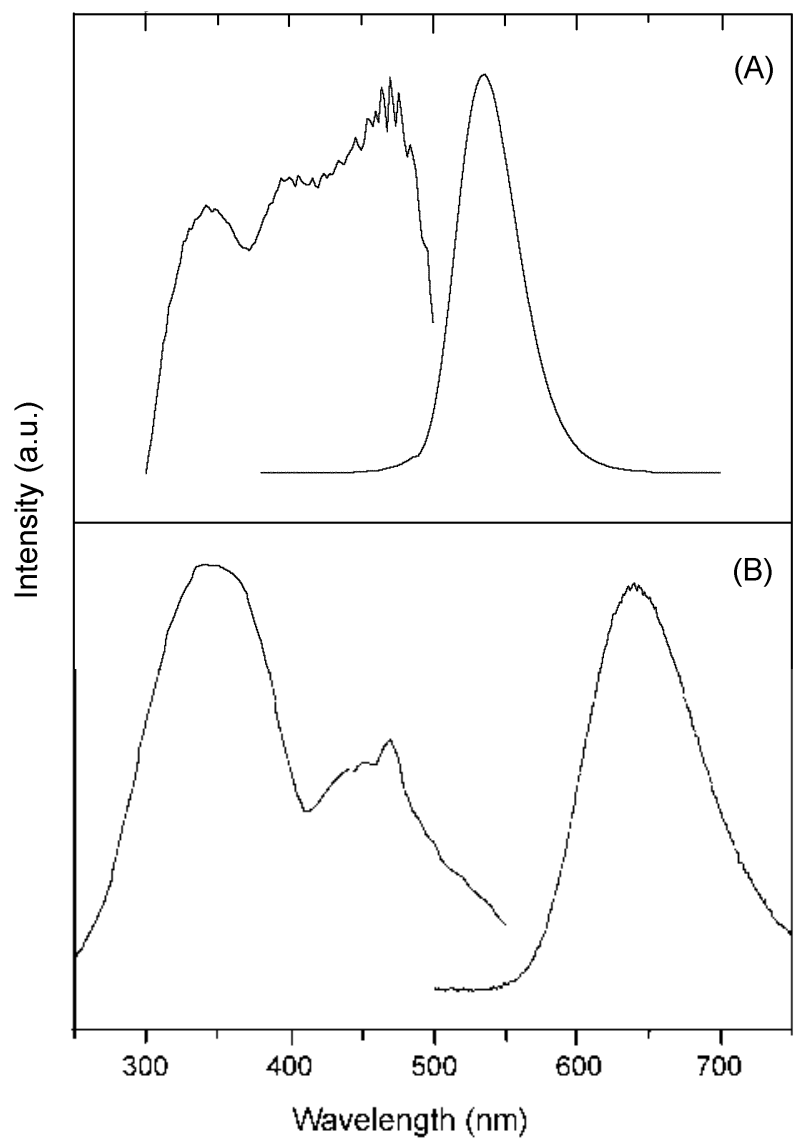

Figure 1. Excitation and cmission spectra of $(\Lambda)$ SrGal $S_{4}:$ Lu and (B) $\mathrm{SrY}_{2} \mathrm{~S}_{4}$ :Eu phosphors. The excitation wavelength is $465 \mathrm{~nm}$. The excitation spectra of (A) $\mathrm{Sr}_{\mathrm{C}} \mathrm{a}_{2} \mathrm{~S}_{4}$ F. Fu and (B) $\mathrm{SrY}_{2} \mathrm{~S}_{4}: \mathrm{Fu}_{4}$ phosphors monitor the emission al $535 \mathrm{~nm}$ and $640 \mathrm{~nm}$. respectively.

$\mathrm{SrGa}_{2} \mathrm{~S}_{1}: \mathrm{Eu}$ phosphor films applied to the blue LED, the intensity of the $465 \mathrm{~nm}$ emission decreases and that of the $535 \mathrm{~nm}$ emission increases. The ClE (Commission International de l'Eclairage) chromaticity coordinates of the photoluminescence spectra are shown in Figure 3(A). The CIE chromaticity coordinates of a blue LED are $x-0.13, y$ -0.08 . As the amount of $\mathrm{SrGa}_{2} \mathrm{~S}_{1}:$ Eu phosphor is increased, the CIE chromaticity coordinates shift to $\mathrm{x}-0.27, \mathrm{y}-0.69$. which correspond to those of the pure green-emitting $\mathrm{SrGa}_{2} \mathrm{~S}_{1}$ : Eu phosphor. In addition, the trend in the chromaticity coordinates with increasing amounts of $\mathrm{SrGa}_{2} \mathrm{~S}_{1}: \mathrm{Eu}$ phosphor is close to the straight line connecting the points of the blue LED and the green-emitting $\mathrm{SrGa}_{2} \mathrm{~S}_{1}:$ Eu phosphor. The $\mathrm{SrGa}_{2} \mathrm{~S}_{1}:$ Eu phosphor used in the present work has a better chromaticity than those of the commercial green phosphors $\mathrm{ZnS}: \mathrm{Cu}$ and $\mathrm{ZnS}: \mathrm{Cu} . \mathrm{Al}$ (ClE chromaticity coordinates of $x-0.28, y-0.53$ and $x-0.29, y-0.61$. respectively)..$^{15,14}$

Figure 2(B) shows the PL spectra of blue- and redemitting LEDs prepared by coating the blue LED with increasing anounts of $\mathrm{SrY}_{2} \mathrm{~S}_{1}$ :Eu phosphor. As the annount of $\mathrm{Sr}_{2} \mathrm{~S}_{4}: \mathrm{Eu}$ phosphor is increased, the intensity of the 465 nım peak decreases and that of the 640 nın peak increases.

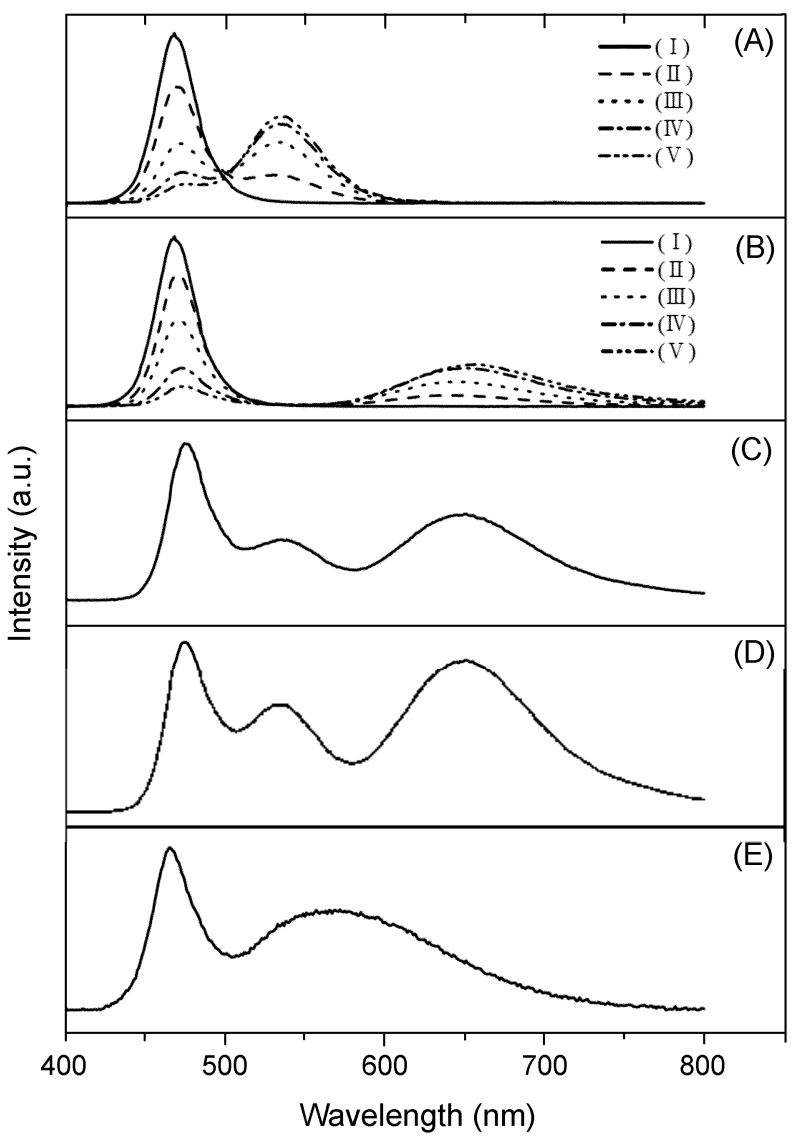

Figure 2. (A. B) Photolumineseence spectra of $(A)$ blue- and green-emitting LEDs. and (B) bluc- and red-emitting LEDs. where $\mathrm{SrGa}_{2} \mathrm{~S}_{4}:$ Fu (greer) or $\mathrm{Sr}_{2} \mathrm{~S}_{4}: \mathrm{Fu}$ (red) phosphor lijms are coated to a blue I, J:I). No phosphor is used in (I). 'l'he amount of phosphor increases on going from (II) to (V). (C. D) Photoluminescence spectra of three-band white LEDs with color temperatures of (C) $5620 \mathrm{~K}$ and (D) $4550 \mathrm{~K}$. where the ratio of $\mathrm{SrCa}_{2} \mathrm{~S}_{4}: \mathrm{Fu}$ to $\mathrm{SrY}_{2} \mathrm{~S}_{1} \mathrm{i}$ :u is lixed at 0.2. and larger amouns of the phosphors are used in (D). (E) Photoluminesennes spectrum of a two-band white LED with a color temperature of $5240 \mathrm{~K}$ in which the $\left(\mathrm{Y}_{00}\left(\mathrm{id}_{03}\right)_{2}{ }_{7} \mathrm{Al}_{5} \mathrm{O}_{12}: \mathrm{Ce}_{0,3}(y\right.$ ellow $)$ phosphor was used.

The CIE chromaticity coordinates converge to those of pure red-emitting $\mathrm{Sr}_{2} \mathrm{~S}_{2}$ : Eu phosphor $(\mathrm{x}-0.65, \mathrm{y}-0.33)$ as the amount of $\mathrm{Sr}_{2} \mathrm{~S}_{1}: \mathrm{Eu}$ phosphor increases, as shown in Figure 3(B). Mueller-Mach $e t \mathrm{al}$. generated white light by combining a blue LED $(460 \mathrm{~nm})$ with $\mathrm{SrGa}_{2} \mathrm{~S}_{1}: \mathrm{Eu}$ (green) and SrS:Eu (red) phosphors. ${ }^{9}$ The excitation spectrum of the SrS:Eu phosphor consists of extremely broad bands that extend up to $600 \mathrm{~nm}$. As a result. the SrS:Eu phosphor is excited not only by the blue LED, but also by the greenemitting $\mathrm{SrGa}_{2} \mathrm{~S}_{4}: \mathrm{Eu}$ phosphor. Because the excitation spectrum of the $\mathrm{SrY}_{2} \mathrm{~S}_{4}: E u$ phosphor used in the present work extends up to $550 \mathrm{~nm}$, the $\mathrm{SrY}_{2} \mathrm{~S}_{1}: \mathrm{Eu}$ phosphor is also excited by the green-emitting $\mathrm{SrGa}_{2} \mathrm{~S}_{1}$ : Eu phosphor. However. this effect is a sinaller than that of the SrS:Eu phosphor on the $\mathrm{SrGa}_{2} \mathrm{~S}_{1}:$ Eu phosphor. In addition, the chromaticity coordinates of the $\mathrm{SrY}_{2} \mathrm{~S}_{4}: \mathrm{Eu}$ phosphor used in the present work are better than those of the $\mathrm{ZnCdS}: \mathrm{Ag}, \mathrm{Cl}$ phosphor ( $\mathrm{x}$ $-0.61, y-0.39)$, which has also been used as the red- 


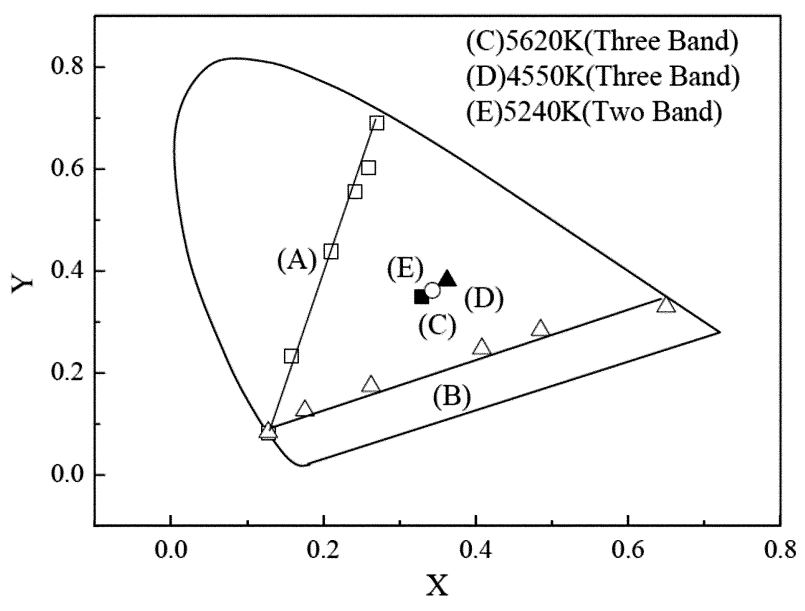

Figure 3. $(A)$ Chromaticity coordinates $(x, y)$ of bluc- and greencnitting LEDs varies from $(0.13 .0 .08)$. correponding to the blu I.F.D alone, to $(0.27,0.69)$. corresponding to the pure $\mathrm{SrGa}_{2} \mathrm{~S}_{4}: \mathrm{Fu}$ phosphor, as the amount of $\mathrm{SrGa}_{2} \mathrm{~S}_{4} \mathrm{i}$.u phosphor is increatsed. (B) CIL chromaticity coordinates of blue- and red-emitting LLDs. where $(x . y)$ varies from $(0.13 .0 .08)$ to $(0.65 .0 .33)$ as the anount of $\mathrm{SrY}_{2} \mathrm{~S}_{4}: \mathrm{F}$.u phosphor is increased. (C, D) CIF chromaticily coordinates of (C) at three-band white I.FI) with $5620 \mathrm{~K}$. (I) a three-band white LED wisth $4550 \mathrm{~K}$. and (E) a two-band white LLD) with $5240 \mathrm{~K}$

emitting phosphor in a three-band LED. ${ }^{(6)}$ Therefore, $\mathrm{Sr}_{2} \mathrm{~S}_{1}$ : Eu phosphor is an excellent red-emitting phosphor for use in conjunction with a blue LED and a green-emitting $\mathrm{Sr}_{1} \mathrm{Ga}_{2} \mathrm{~S}_{1}: \mathrm{E} u$ phosphor to generate a three-band white LED.

Figures 2(C) and 2(D) show the PL spectra of three-band white LEDs in which the ratio of $\mathrm{SrGa}_{2} \mathrm{~S}_{1}: E u$ to $\mathrm{Sr}_{2} \mathrm{Y}_{2} \mathrm{~S}_{1}: \mathrm{Eu}$ was fixed at 0.2. and where the total amount of phosphors used in (D) is 1.25 times of that in (C). The CIE chromaticity coordinates of these LEDs are $x=0.33, y=0.35$ and $x=$ $0.36, y=0.38$, as shown in Figure $3(C)$ and $3(D)$, respectively. The colors of white light sources are generally expressed in terms of the color temperatures with CIE chromaticity coordinates. The color temperatures of the three-band white LEDs in Figure 2(C) and 2(D) are $5620 \mathrm{~K}$ and $4550 \mathrm{~K}$, respectively. Therefore, by controlling the relative amounts of $\mathrm{SrGa}_{2} \mathrm{~S}_{1}: \mathrm{Eu}$ and $\mathrm{SrY}_{2} \mathrm{~S}_{1}:$ Eu phosphors as well as the total combined amount of the two phosphors, we can vary the color temperature of the white emitting LED.

Adjusting the color temperature of a conventional twoband white LED entails preparing a new sample of yttrium aluminum garnet $(\mathrm{YAG})_{2}\left(\mathrm{Y}_{1-\mathrm{Y}} \mathrm{K} \mathrm{Gd}_{\mathrm{X}}\right)_{3}\left(\mathrm{Al}_{1-\mathrm{Y}} \mathrm{GaY}\right)_{5} \mathrm{O}_{12}: \mathrm{Ce}$ with different proportions of the various components. When the content of $\mathrm{Gd}$ is increased in $\left(\mathrm{Y}_{1-\mathrm{X}} \mathrm{GdX}\right) \mathrm{Al}_{5} \mathrm{O}_{12}$ : $\mathrm{Ce}$ phosphors. the peak emission wavelength is red shifted from $530 \mathrm{~nm}$ to wavelengths up to $570 \mathrm{~nm}$. On the other hand, increasing the Ga content in $\mathrm{Y}_{3}\left(\mathrm{Al}_{1-Y} \mathrm{Giay}_{\mathrm{Y}}\right)_{5} \mathrm{O}_{12}$ : Ce phosphors causes a blue shift in the peak emission wavelength. Therefore, the color temperature of the white light can be decreased by increasing the amount of $\mathrm{Gd}$ and decreasing the amount of $\mathrm{Ga}$ in the $\left(\mathrm{Y}_{1-X} \mathrm{Gd} X\right)_{5}\left(\mathrm{Al}_{1-Y} \mathrm{Ga}_{Y}\right)_{5} \mathrm{O}_{12}: \mathrm{Ce}$ phosphor coated onto the blue LED, and vice versa. ${ }^{15}$ Figure $2(\mathrm{E})$ shows the

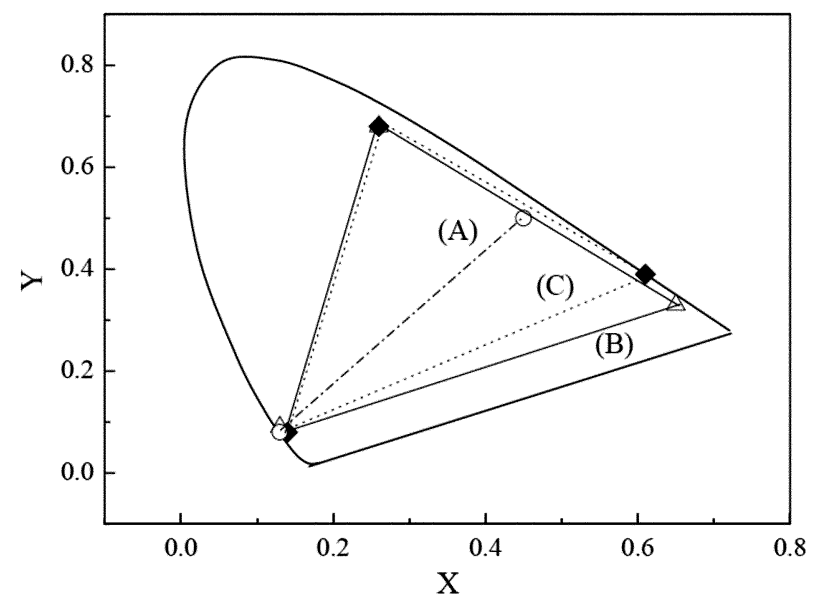

Figure 4. CIE chromaticity coordinates of (A) a two-band LED (blue I.F.D) + $\mathrm{Y}_{3} \mathrm{Al}_{3} \mathrm{O}_{12}: \mathrm{Ce}$ ). (B) a three-band I.F.D (blue I.F.D +

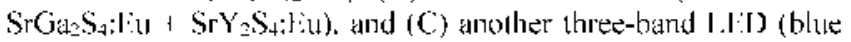
LLD + SrGas $\left.S_{1}: \mathrm{Eu}+\mathrm{ZnCdS:} \wedge \mathrm{g} . \mathrm{Cl}\right)$

P'L spectrum of a two-band white LED comprised of a blue $\mathrm{LED}$ and $\left(\mathrm{Y}_{0.6} \mathrm{Gid}_{0.1}\right)_{2.7} \mathrm{Al}_{5} \mathrm{O}_{12}: \mathrm{Ce}_{0.3}$ phosphor, which has a color temperature of $5240 \mathrm{~K}$. Its ClE chromaticity coordinates are shown in Figure $3(\mathrm{E})$. In contrast to the effort required to vary the color temperature of a two-band white LED, the color temperature of the three-band white LED reported here can be easily varied by simply mixing the different amounts of phosphors and/or varying the total amount of phosphor coated onto the blue LED. This represents a key advantage of the three-band white LED over the two-band white LED.

Figure 4 shows a chromaticity diagram depicting the chromaticity coordinates of a two-band LED (blue LED + $\left.\mathrm{Y}_{3} \mathrm{Al}_{S} \mathrm{O}_{12}: \mathrm{Ce}\right)$, the three-band LED developed in the present work (blue LED + $\mathrm{SrGa}_{2} \mathrm{~S}_{1}: \mathrm{Eu}+\mathrm{SrY}_{2} \mathrm{~S}_{1}: \mathrm{Eu}$ ), and a threeband LED developed previously (blue $\mathrm{LED}+\mathrm{SrGa}_{2} \mathrm{~S}_{1}: \mathrm{Eu}+$ $\angle \mathrm{nCdS}: \mathrm{Ag}, \mathrm{Cl}){ }^{10,15}$ The color range of the light emitted by the two-band LED is shown in the chromaticity diagram as a line connecting the positions of the blue LED and $\mathrm{Y}_{3} \mathrm{Al}_{S} \mathrm{O}_{12}: \mathrm{Ce}$ (yellow) phosphor. Similarly, the color range of each three-band LED is shown as the region inside the triangle drawn by connecting the positions of the blue LED, the green phosphor, and the red phosphor. Of the three LEDs shown in Figure 4, the color range of the blue LED + $\mathrm{SrGa}_{2} \mathrm{~S}_{4}: \mathrm{Eu}-\mathrm{SrY}_{2} \mathrm{~S}_{1}: \mathrm{Eu}$ three-band LED is the widest, and hence this LED has the best color purity. The superior color properties of the three-band LED developed in the present work (blue LED - $\mathrm{SiGa}_{2} \mathrm{~S}_{4}: \mathrm{Eu}+\mathrm{SrY}_{2} \mathrm{~S}_{1}: \mathrm{Eu}$ ) make it a good candidate for use as a backlight source in small full-color display devices such as personal digital assistants.

\section{References}

1. Nakamura. S.: Senob. M.: Iwasa N.: Nagahama. S.: Yamada. T.: Mukiai, T. Jpn. J. Appl. Phs. 1995 34. 1.1332.

2. Nakamura. S.: Senob. W.: Iwatsa. N.: Nagahama S. dppl. Phys. lett. 1995.67 .1868$.

3. Schlotter: P.: Baur. J.: Hielscher. Ch.: Kunzer. M.: Obloh. H.: Schmidt. R.: Schneider. 1. Hater: Sci. Eng. 1999. B59. 390. 
4. Yum, I. H: Seo. S. Y: Lee, S.: Sung. Y. E. J. Electrochem. Soc. 2003. 150. H47.

5. Park. J. K.: Kim. C. H.: Park. S. H.: Park. H. D.: Choi. S. Y. Appl. Phvs. Lett. 2004. 84. 1647.

6. Tamula. T.: Setomoto, T: Taguchi. T. J. Limin. 2000. 87-89. 1180 .

7. Sato, Y: Takahashi. N.: Sato. S. Jpn. J. Appl. Phs. 1996, 35. L838.

8. Nishida. T.: Ban. T.: Kobayashi. N. Appl. Plns. Lett. 2003. 82.3817.

9. Mueller-Mach. R.: Mueller. G. O.: Krames. M. R.: Trottier. T. IEEE J. Ouan. Elect. 2002, 8.339.
10. Huh. Y. D.: Shim, J. H: Kim. Y.: Do, Y. R. J. Electochem. Soc 2003. $150 . \mathrm{H} 57$.

11. Do. Y. R.: Bae. I. W.: Kim. Y: Yang. H. G. Bull. Korean Chen Soc. 2000. 21. 295

12. Do. Y. R. J. Electrochem. Soc. 2000. 147, 1597.

13. Jians. Y. D.; Villaobos, G.; Souriau. J. C.: Paris. H.: Summers. C. J. Wang. Z. L. Solid State Commun. 2000, 113. 475.

14. Yang. S.: Stoffers. C.: Zhang. F.: Jacobsen. S. M.: Wagner. B. K.: Summers. C. T.: Yocom. N. Appl. Plns Lett. 1998. 72.158.

15. Huh. Y. D.: Cho. Y. S.: Do. Y. R. Bull Korean Chem. Soc. 2002. 23. 1435 